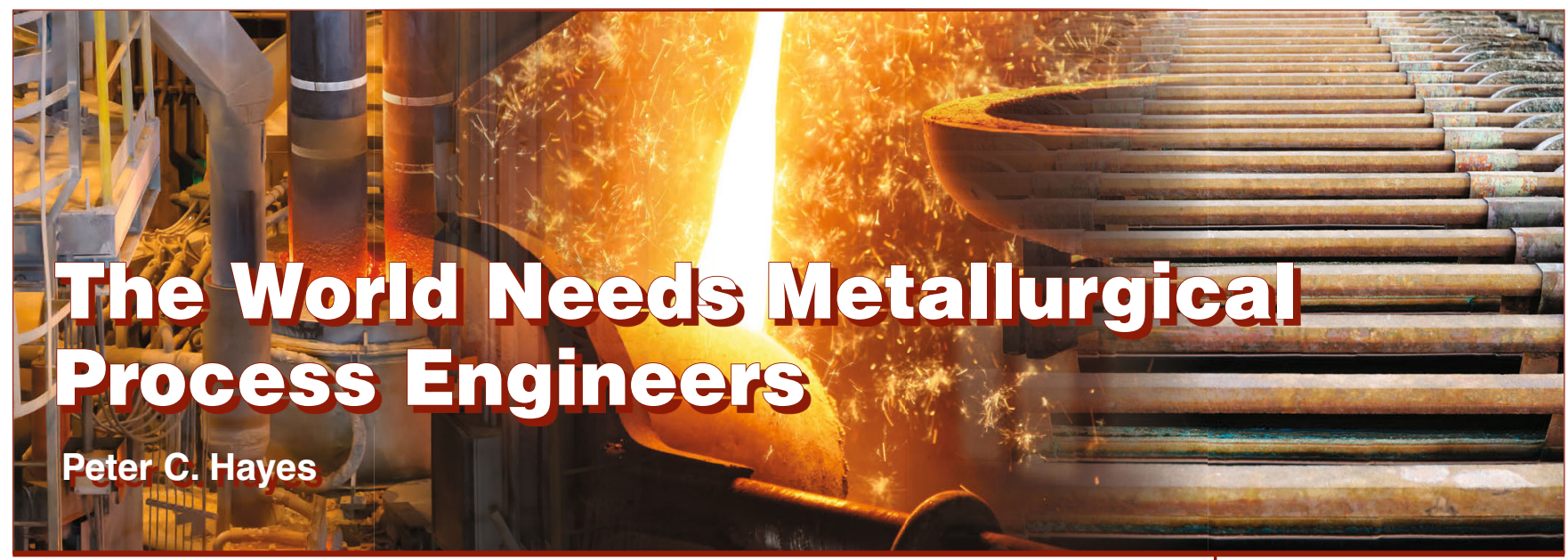

\section{The Changing World}

On the face of it, the metallurgical industry looks stronger than at any time in its development. Primary metal production is at record levels, and continues to expand in response to significant population and consumption growth. The rapid technological changes that are currently underway are creating new markets for metals.

The industry response to this demand will be increased investment in exploration and the discovery of new primary sources in the form of ore bodies. However, we can expect that as these finite sources are consumed, there will be further declines in mean ore grades. Without major technological innovations this trend means that, to maintain the same levels of production, there will be increased energy usage, and with it increased costs and the potential for greater environmental impacts. The problems will be most acute for nonferrous metals and those metals that are present in low concentrations in ores. The use and treatment of polymetallic ores will increase. Raw materials will be of greater complexity in terms of both microstructure and composition over those that have been used in recent times. These factors will create a need for further technological development and metallurgical innovation to be able to efficiently process these materials.

The profile of the metallurgical industries in Europe and the United States has changed significantly from one of primary metal production to manufacturing. Metallurgical engineers have played a key role in the development of new advanced materials and manufacturing technologies, creating opportunities for new industries in a diverse range of engineering applications. The advent of computerization and new technologies for energy generation and storage are already stimulating the need for new process technologies to produce a wide range of metallic elements - elements that, even in the recent past, have been regarded as being of no more than intellectual or academic interest.

Although small in volume, these are high value products, critical for the sustainability of our technologically advanced societies. Examples of these metals include, in photovoltaics - indium, gallium, germanium, silicon, silver; in electric vehicles and batteries - cobalt, copper, lithium, rare earth elements, vanadium; in fuel cells - gold, palladium, platinum, ruthenium; thermo- and optoelectrics - bismuth, antimony, arsenic, gallium, selenium, tellurium. These metals are needed in the form of pure metals, compounds, and solutions to tight chemical and physical specifications for each of these different manufacturing applications.

In Europe, issues such as materials scarcity and concerns over the supply of critical metals have prompted strategic moves involving both government and industry towards creating a circular economy; one in which waste and energy usage is minimized, and metal and materials recycling are maximized. These initiatives, and the need for industry, university, and government cooperation are exemplified by the establishment of the European Institute

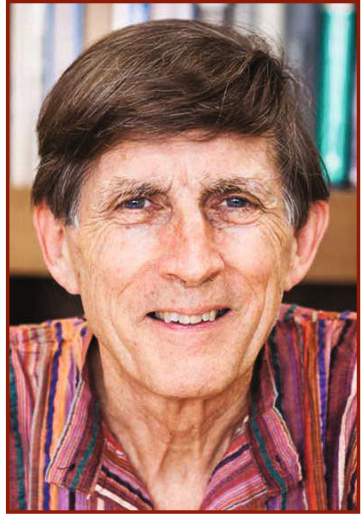

Peter Hayes

Editor's Note:This article is based on the keynote lecture, "The Changing World of Metallurgical Education, delivered by Peter Hayes at a joint session of the 7th International Symposium on Advances in Sulfide Smelting and the Peter Hayes Symposium on Pyrometallurgical Processing at Extraction 2018 held in August 2018. Comments were provided by the following discussion panel: Bart Blanpain (Leuven University); Kenneth Coley (McMaster University); Mario Loebbus (Aurubis); Sari Muinonen (Glencore); and Maurits van Camp (Umicore). Extraction $\mathbf{2 0 1 8}$ was organized by The Metallurgy and Materials Society (MetSoc) of the Canadian Institute of Mining, Metallurgy and Petroleum (CIM); the Society for Mining, Metallurgy \& Exploration (SME); and TMS. 
Do You Have a Perspective to Share? JOM: The
Magazine is
seeking case studies, member perspectives, and nontechnical project overviews with strong industrial applications. To suggest an article idea, contact Kaitlin Calva, JOM Magazine Managing Editor, at kcalva@ $@$ tms.org. of Innovation and Technology (EIT). Within this Institute, "raw materials" was designated as one of the key Knowledge and Innovation Communities charged with assisting the drive towards the circular economy. ${ }^{1}$

The underlying message is clear. Our technologically based society cannot be sustained without the continued supply of metals from both primary and secondary sources. Metallurgical engineers are needed to provide innovative solutions to the emerging and complex challenges faced by the industry.

\section{Status of Metallurgical Education Programs}

Over the past 100 years, the principal pathways that have been developed for the education of our young engineers have been through tertiary institutions, our colleges and universities. In general, the standards of training of professional engineers have never been higher. All recognized engineering programs are subject to rigorous scrutiny by accreditation panels representing the various engineering professions. Accredited learning programs must fulfill minimum standards of learning outcomes covering fundamental and specialist knowledge, graduate attributes and professional engineering skills. ${ }^{2-4}$ Major efforts are being made across all tertiary institutions to improve teaching and learning practice, to enhance the quality of deep learning and provide the foundations for lifelong learning.

However, if we examine the structure and content of metallurgical engineering programs, we find, particularly in the United States and Europe, that the majority have morphed over time into materials science and engineering (MSE) programs -a matrix of disciplines that are related through the common elements of structure/ composition; properties; performance, and product synthesis. ${ }^{5}$ This change has been driven by major investments into the research and development of new materials, and their application to new manufacturing technologies. While the expansion and growth of metallurgical education into these new areas is welcome, close examination reveals a marked decline in teaching, and in research and development capabilities in core aspects of metallurgical process engineering. ${ }^{6}$ Metallurgical process engineering has been reduced to a minor component of most of these MSE teaching and learning programs, and in many cases, key courses have disappeared from the curriculum. There has been a marked decline in student enrollments in metallurgical process engineering programs in industrialized countries.

In addition, those countries whose economies rely on primary metal production in general, do not have the financial resources or education infrastructures strong enough to establish and sustain strong mineral processing and metallurgical process engineering programs.

Across the globe, the strong support previously given by industry for mining and metallurgical education has faded. Schools of Mines, once the source of skilled workforces for primary production, have been closed. The numbers of academic positions at universities supported by industry have declined. The result is that, internationally, with the few exceptions of countries having centrally controlled economies, there has been a decline in financial resources directed towards providing opportunities for future metallurgical engineering professionals. In short, the quality and sustainability of metallurgical engineering education in most regions of the world are under threat at the very time that innovation and the ability to meet major technical challenges are becoming the central tenants to the future of the industry. Industry will be the first to lose if the availability of welltrained metallurgical engineers continues to decline. Those companies and countries that invest in their workforce are the ones most likely to survive the emerging challenges and to take advantage of the business opportunities ahead.

A concerted effort is needed by industry, professional societies, and academia to promote and sustain the education and research capacities in the field of metallurgical process engineering at our tertiary institutions. 


\section{Metallurgists of the Future}

If the need for continued metallurgical education is accepted, it is timely to ask some important questions. What knowledge, skills, and attributes do we need from our future metallurgical engineering workforce to prepare them for the challenges that lie ahead? How are we to ensure that we provide appropriate learning and career pathways for future professional metallurgical engineers? We need metallurgical engineers who can understand and provide innovative solutions to complex problems, and who can adapt to the rapid changes in technologies.

All metallurgical engineers need a background and understanding of mathematics, the basic sciences, materials, and other engineering sciences in order to be able to communicate and effectively work with other professionals in the industry. Some would argue that a general engineering education is sufficient.

However, the metallurgical industry also needs engineers with specialist knowledge and advanced skills in mineral (physical) processing, hydro/electro-metallurgy, and pyrometallurgy. In order to truly understand metallurgical processes and have an appreciation of the potential for process improvement, a graduate engineer should have an understanding of the whole value chain.

The metallurgist of the future will spend more time utilizing the powerful computer tools that have become available through the digital revolution rather than patrolling the shop floor controlling individual unit operations. Using these sophisticated computer-based tools to analyze complex data sets and predict process outcomes, metallurgical engineers can play a key role in increasing the productivities of integrated operations and/or optimizing the overall financial returns of these operations. ${ }^{7}$ The ability to apply these principles to different physical and chemical systems can be provided by integrating this specialist metallurgical knowledge with core process engineering knowledge and skills in chemical thermodynamics, mass and energy transport, reaction kinetics, process control, systems engineering analysis,

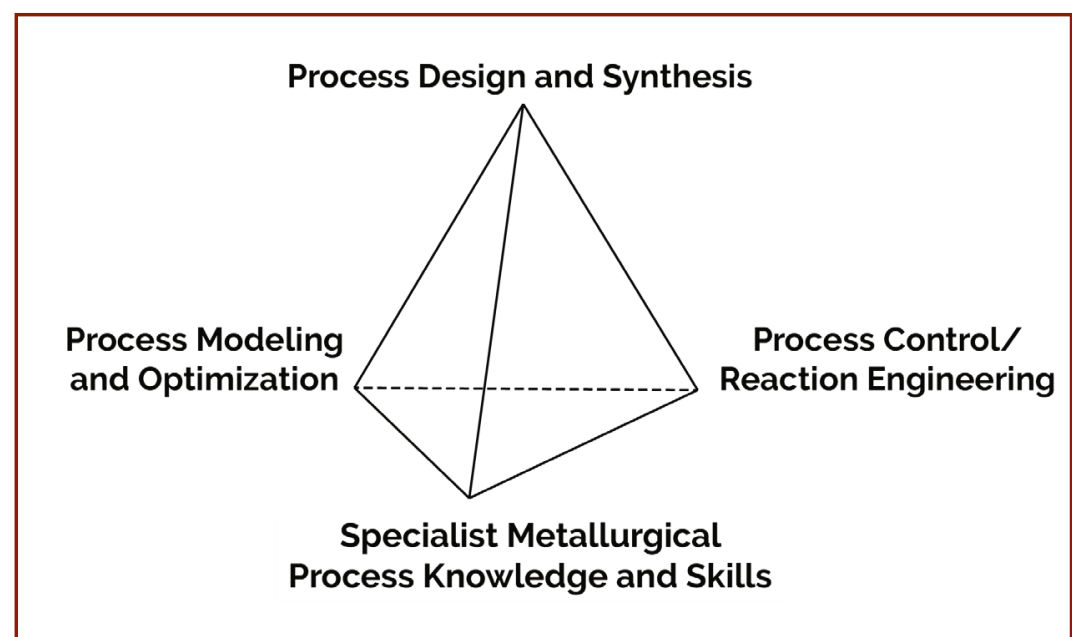

problem solving, and synthesis.

The common features that could be used to define the metallurgical process engineering (MPE) programs for the future, and the core knowledge and skills needed, can be summarized by four interrelated areas: specialist metallurgical process knowledge and skills; process control/ reaction engineering; process modeling and optimization; and process design and synthesis (see Figure 1).

It is not by chance that many of these areas of knowledge and core skills are common to chemical engineering graduates. That discipline has been successful in transforming itself from its origins in applied chemistry to encompassing a wide range of process industries that include petroleum, oil and gas, polymers, inorganic chemicals, biotechnology, environmental engineering, and new materials. It is time to combine the strengths of process and systems thinking, which are at the heart of modern chemical engineering, with specialist metallurgy knowledge and skills, to reinvigorate the metallurgical process engineering discipline. In this way, we can create educational structures that embrace the needs of the current and the future metallurgical industry.

A flexible yet sound and robust structure can be built by utilizing the strengths of process engineering in the early years of the programs. Basic and engineering sciences in year one and process engineering and modeling fundamentals in year two with contextual learning of metallurgical applications. In years three and four, the study plan would include specialist
Figure 1. Common core knowledge and skills that can be used to define and develop metallurgical process engineering (MPE) programs. 


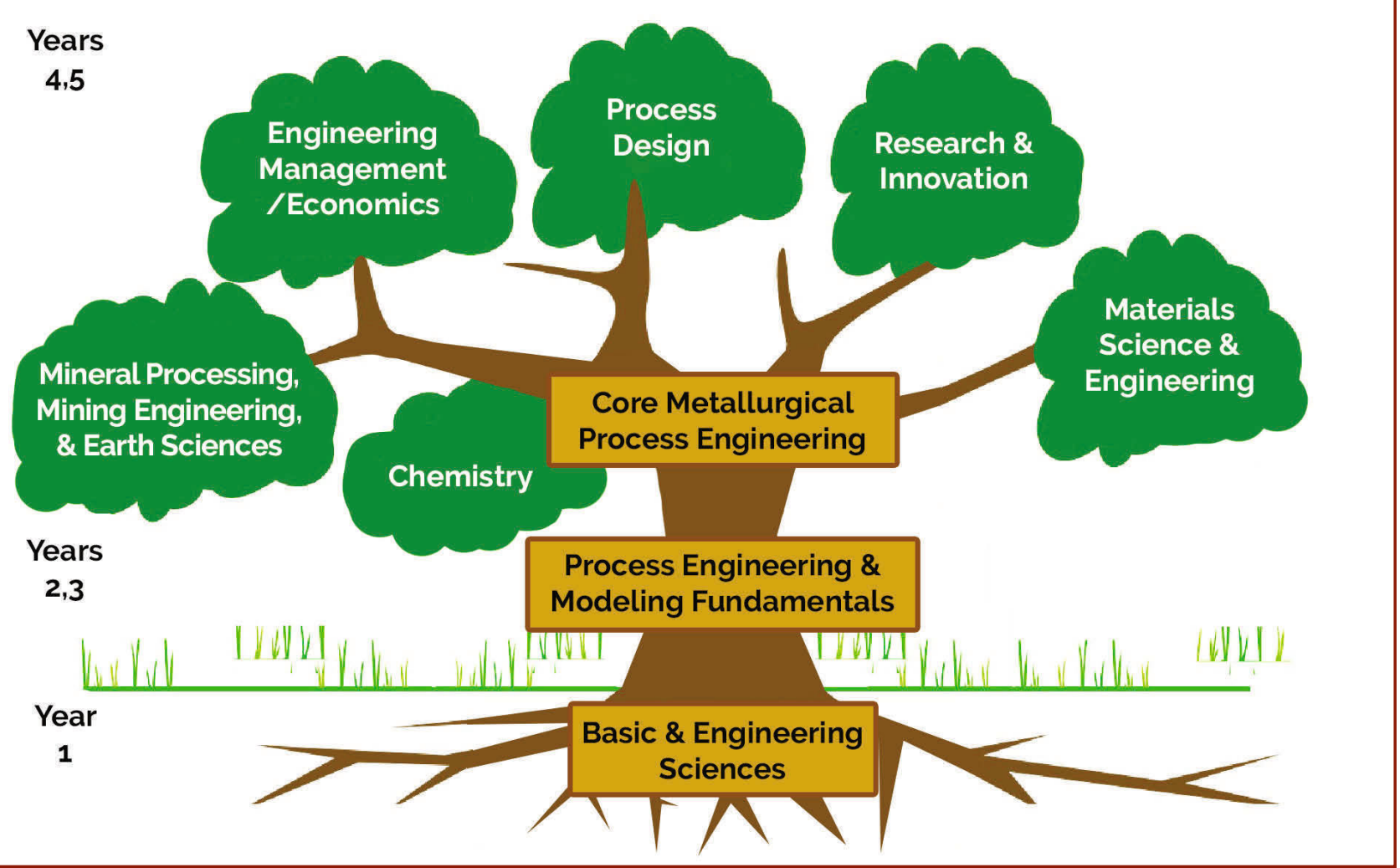

Figure 2. A proposed program structure for bachelor's of engineering metallurgical process engineering programs based on a strong process engineering core with flexibility to cover the many branches and specializations that embody the discipline. metallurgical courses and courses from related disciplines as appropriate for local industry requirements. The proposed structure of such a program, one that incorporates the features of a core of process engineering and broadening through links to different branches and specialist fields of metallurgy, is illustrated schematically in Figure 2. In this way, a strong and sound metallurgical process engineering program can be constructed using, and building on, the existing teaching and learning resources within our engineering faculties. The model provides flexibility that enables individual institutions to offer or develop programs that reflect strengths in particular branches of metallurgical engineering.

This framework could be used to develop four-or five-year bachelor's or B.E./M.E. programs in metallurgical process engineering. The structure is not intended to be prescriptive and may not be suitable or appropriate for all tertiary institutions. It is, however, the basis for the B.E. dual major program in chemical and metallurgical engineering that has been running successfully since 2006 at The University of Queensland.
In practice, the details of programs offered at different institutions will vary depending on local and regional industry needs. In some countries, the focus will be on mineral processing and the preparation of mineral concentrates; in others, the emphasis will be on the development of metal recovery and recycling or new process routes for the production of advanced materials. The point is that a common set of core knowledge and skills is required to be able to tackle these problems as a professional metallurgical engineer.

\section{Essential Elements for the Sustainability of MPE}

Continuing the analogy of the tree (see Figure 3 on the following page), the healthy growth of plants requires the provision of the atmosphere (sun, water, $\mathrm{CO}_{2}$ ) and a fertile environment (essential elements, organic matter, nutrients, microbiological activity). We can draw some useful analogies between this example and the requirements for sustaining metallurgical education. 
In the metallurgical context, the atmosphere that is essential for the growth and sustainability of metallurgical engineering as a discipline is one that includes:

- Acknowledgement at senior leadership (chief executive officer) levels and proactive industry support for metallurgical engineering education

- Creating attractive, challenging, and visible career paths

- Promoting a positive and exciting vision of the ways in which professional metallurgical engineers can contribute to the future sustainability of our society

The fertile environment necessarily includes:

- Ensuring that recognized tertiary institutions have appropriate numbers of academic staff and learning facilities to be able to provide specialist metallurgy learning at undergraduate and postgraduate levels

- Active engagement between university/ industry to identify the challenges faced by the minerals, primary and recycled metals, and advanced materials industries

- Providing supportive learning environments and collaborations between complimentary academic disciplines, e.g., MSE programs and chemical engineering departments

- Providing appropriate funding models to sustain undergraduate and postgraduate process metallurgy programs

\section{Strategies to Develop Our Future Workforce}

A major issue is attracting sufficient young would-be engineers into metallurgical engineering programs. For this to occur, there has to be a significant change in perceptions on their part. The industry needs to embrace a new vision and demonstrate that the focus is just not about making money-young people want to feel that they are genuinely playing a part in shaping the future. We need to excite their interest; to show them how they can utilize their skills in creating a sustainable society and a healthier environment.

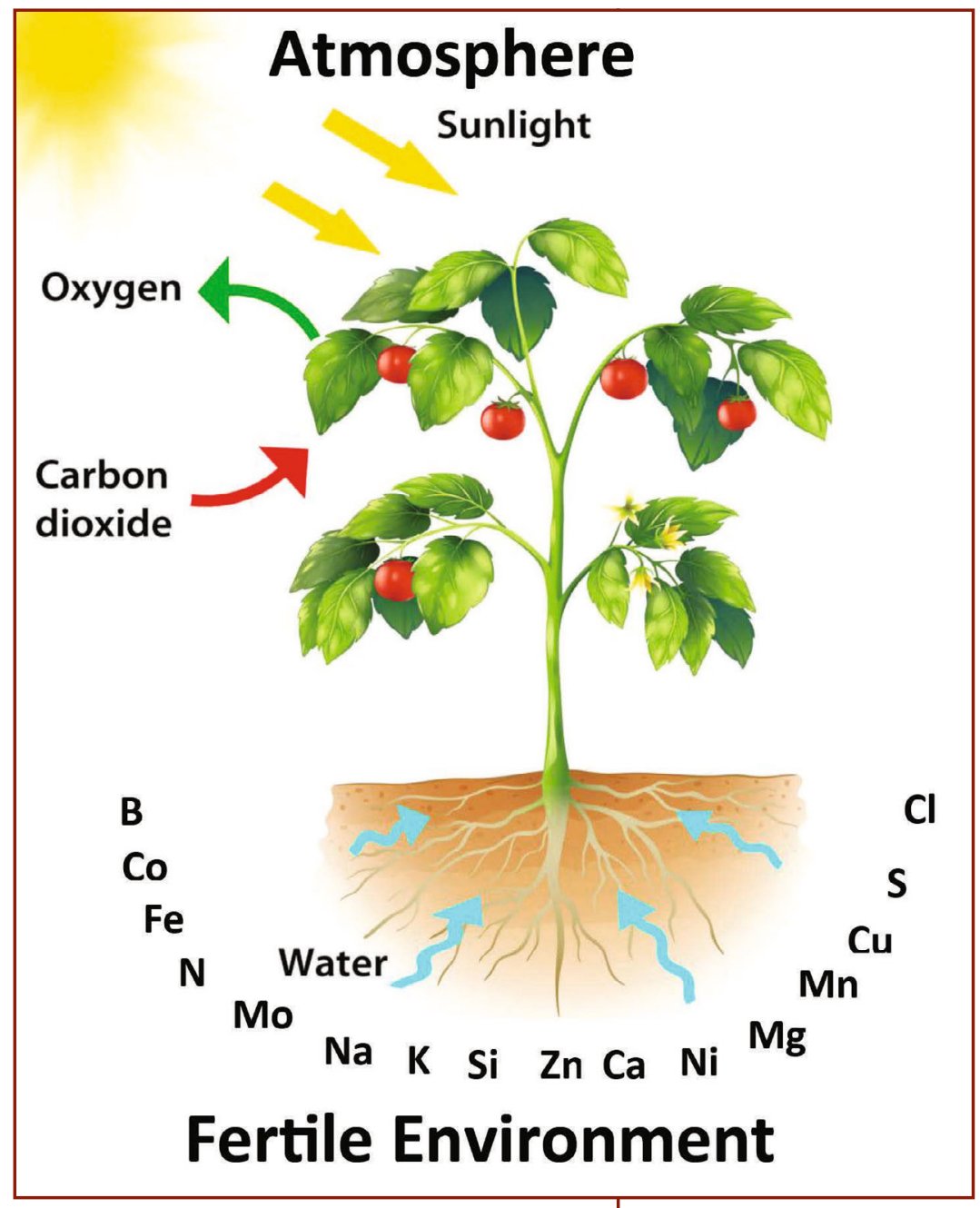

Most university programs are active in recruiting students whenever and wherever they can, since their funding is principally based on enrolment numbers. Potential actions by universities to re-establish the profile of metallurgical process engineering include:

- Re-establishing attractive undergraduate majors in MPE programs with a focus on core metallurgical and process engineering skills

- Developing flexible entry and pathways into MPE programs

- Articulating clear, exciting career pathways and opportunities for graduates

- Promoting and marketing a positive view of the future of the metallurgical industry
Figure 3. The essential conditions for the healthy growth of plants, which provides a useful analogy for the requirements for sustaining metallurgical education. 
The numbers of students expected in these MPE programs are small relative to other engineering disciplines, which makes them hard to justify to university management. For this reason alone, the establishment of MPE programs needs additional moral and financial support from the minerals and metallurgical industries.

Potential actions by industry include:

- Actively supporting and engaging with academic and research staff through funding industry focused research

- Providing industry-funded academic positions in specialist fields of metallurgical engineering

- Developing long-term partnerships in support of research and development strengths in fundamental research in selected core fields of expertise

- Attracting prospective students into the industry through providing and supporting quality industrial work experiences and internships for early year $(1,2,3)$ undergraduate students

- Providing mentoring, technical development, engineering skills and career guidance to early career graduate engineers

- Establishing continuing professional development programs within companies that support deep learning of advanced skills

- Establishing good relationships and ongoing dialogue between senior management in companies and universities, to provide a mechanism of explaining industry needs and opportunities for collaborations

\section{Summary}

The world needs metallurgical process engineers to ensure continued metal resource supply and sustainability of our technologically based society.

This will require concerted efforts by industry, professional societies, and academia across the globe to promote and sustain the education and research capacities in the field of metallurgical process engineering at our tertiary institutions.
In this article, I have put forward some thoughts about the knowledge, skills, and attributes needed in our future metallurgical engineering workforce and proposed a flexible educational structure, based on process metallurgy, that could be used to deliver the next generation of engineers. I look forward to hearing other ideas on how we can meet these goals, actions, and initiatives that can be taken so that we can address the rapid changes faced by the modern metallurgical industry, and move closer to the economic, technical, and social sustainability of our society.

\section{End Notes}

1. EIT, European Institute of Innovation and Technology, https://eit.europa.eu/eit-community leit-raw-materials.

2. ABET, Accreditation Board for Engineering and Technology, Engineering Accreditation Commission, www.abet.org/.

3. EA, Engineers Australia, www.engineersaustralia.org.au/.

4. Institution of Chemical Engineers (IChem E), www.icheme.org/.

5. M.C. Flemings, "What Next for Departments of Materials Science and Engineering?", Annu. Rev. Mater. Sci. 1999, vol. 29, pp.1-23.

6. P.C. Hayes, "The Changing World of Metallurgical Education," Extraction 2018, 2018, pp. 57-67.

7. E. Jak, "The Role of Research in Pyrometallurgy Technology Development from Fundamentals to Process ImprovementsFuture Opportunities," Extraction 2018, 2018, pp.19-37.

Peter Hayes is professor of metallurgical engineering within the School of Chemical Engineering at The University of Queensland, Brisbane, Australia. He is currently the Metallurgical Engineering Program leader and is senior researcher in the Pyrometallurgy Innovation Centre (PYROSEARCH) at the university. He has been an active TMS member since 1986. 